\title{
O teatro de Nelson Rodrigues: crime como redenção?
}

\author{
Patrícia Chiganer Lilenbaum \\ Professora Assistente - Universidade Veiga de Almeida \\ Doutoranda - PUC-RJ
}

Resumo:

O presente artigo aborda crimes, pecados e monstruosidades na obra teatral de Nelson Rodrigues com o objetivo de refletir sobre o significado desses termos e sua utilidade para a compreensão do teatro rodriguiano. A principal peça enfocada é a primeira e pouco lembrada $A$ mulher sem pecado, de 1942, que já traz, embrionariamente, as temáticas obsessivas do teatro do dramaturgo.

Palavras-chave: Teatro; catarse; obsessão; crime

Para salvar a platéia, é preciso encher o palco de assassinos, de adúltero, de insanos e, em suma, de uma rajada de monstros.

Nelson Rodrigues

A obra teatral de Nelson Rodrigues é plena de pequenos monstros, grandes pecadores e crimes demasiadamente humanos. Poderíamos ponderar que um crime é sempre humano, pois é um conceito para uma ação condenável do próprio homem. Outras espécies não cometem crimes. Contudo, os principais crimes no teatro rodriguiano raramente são caso de polícia, embora haja, em profusão, corrupção, assassinatos, prostituição, traições, incestos, violações e o que poderia se considerado, em linguagem antiquada mas legalmente aceita, crime contra a honra e atentado ao pudor. Os pequenos monstros e os grandes pecadores estão ocupados, na verdade, com crimes para o qual não há prisão nem fiança: todos se deixam levar por suas mais profundas obsessões e são dominados pelo lado reprimido e obscuro do ser humano.

Primeiramente, seguiremos as seguintes e simples definições e diferenciações: um crime é um ato condenável sob a ótica da lei de uma sociedade; um pecado é um ato condenável sob a ótica de uma religião; por fim, uma monstruosidade, de definição mais vaga, seria um ato considerado abjeto, porque desumano, para além do que se espera do humano, o que tornaria esse ato uma 
manifestação do mal e do desconhecido. Dessa forma, crimes e pecados parecem ser previsíveis e definíveis por certas regras; a monstruosidade parece ir além, sendo uma espécie de denominação espontânea do ser humano em face ao terror considerado impossível.

Embora Nelson sempre tenha afirmado desconhecer a obra de Freud, seu teatro parece ter sido moldado pelos complexos de Édipo e de Electra e pelas reflexões de textos como $O$ mal-estar na civilização, em que o pai da psicanálise diagnostica um incômodo permanente na sociedade, resultante de um repressão violenta mas necessária para assegurar o convívio social. Lançar um olhar psicanalítico sobre o teatro rodriguiano é, atualmente, o óbvio ululante, para usar expressão do próprio Nelson, admirador de Fiodor Dostoievski. O título de um dos principais romances do autor russo, Crime e castigo, parece ser o mote adotado pelo autor brasileiro em suas peças: com a exceção de Viúva, porém honesta, Bonitinha, mas ordinária e $O$ anti-Nelson Rodrigues, as peças do dramaturgo não apresentam final feliz, como a reafirmar que ao crime se segue o castigo, não a impunidade. $O$ autor, com seu gosto insuperável para a polêmica, afirmava que, em seus textos,

o desejo é triste, a volúpia é trágica e o crime é o próprio inferno. O espectador vai para casa apavorado com todos os seus pecados passados, presentes e futuros. (...) Minhas peças são obras morais. Deviam ser adotadas na escola primária e nos seminários. ${ }^{1}$

Embora se perceba a ironia dessas palavras, é importante notar que as peças são encaradas como educativas por, justamente, mostrarem que os crimes e pecados não compensam: aqui se faz, aqui se paga. O teatro, cuja função pedagógica de transmissão de valores já foi apontada pelos gregos, agiria como uma demonstração ficcional de que o crime (seja ele de que natureza for) não compensa. É a primeira interpretação que vislumbramos; porém, em se tratando de Nelson, é preciso cuidado para não direcionar essas palavras para uma defesa do status quo, da manutenção dos valores tradicionais.

As famosas frases feitas do autor, por serem lidas literalmente, acabavam por transmitir um espírito reacionário, acusação que Nelson sofreu por décadas. Como já apontado por outros estudiosos, ${ }^{2}$ "as frases têm uma espécie de estrutura do recalque: elas são o oposto do senso-comum, o negativo de um positivo". ${ }^{3}$ Ao afirmar, por exemplo, que "nenhuma mulher trai por amor ou desamor. O que há é o apelo milenar, a nostalgia da prostituta, que existe ainda na mais pura", ${ }^{4}$ Nelson está no contra fluxo do senso-comum, o qual afirma: em primeiro lugar, ser o adultério um ato criminoso e pecaminoso, fruto da falta de amor; em segundo, haver uma diferença clara e fundamental entre as prostitutas e as chamadas mulheres puras. Ao inverter a lógica e embaralhar os contrários, Nelson não deseja realizar uma simples ofensa, mas sim questionar se o adultério é uma simples questão de falta de amor, ou uma reação à repressão sofrida pela mulher, pressionada pelos dois extremos: ou é pura ou é prostituta. Lida sob essa ótica, a frase soa muito mais como uma crítica à sociedade do que à mulher.

\footnotetext{
${ }^{1}$ RODRIGUES. Flor de obsessão: as 1.000 melhores frases de Nelson Rodrigues, p. 109.

2 WALDAMN; VOGT. Nelson Rodrigues: flor de obsessão.

${ }^{3}$ RAMOS. A noiva desnudada, p. 58.

${ }^{4}$ RODRIGUES. Flor de obsessão: as 1.000 melhores frases de Nelson Rodrigues, p. 10.
} 
Sendo assim, ao voltarmos para a afirmação do autor sobre a pretensão pedagógica de suas peças, percebemos que não se trata de condenação do autor a suas personagens nem sua adesão ao discurso moralista. Essas são, antes, condenadas pela sociedade, a qual não admite um final feliz para quem não segue as normas. As peças, nesse caso, apenas demonstrariam o que acontece com quem inflige as regras, como uma análise desesperançada do ser humano e de sua impossibilidade de viver em grupo e ser feliz seguindo leis alheias aos seus desejos. Há, então, um questionamento sobre o que é crime e pecado, o que não se traduz em libertinagem (outra acusação comum). Na obra de Nelson, parece haver uma investigação sobre quais seriam as possibilidades de realização do ser humano: realizar-se seria sinônimo de cometer um crime, um pecado? A satisfação pessoal é condenável? É possível que a redenção tome forma outra que não seja a do crime? É possível ser um criminoso impunemente?

Ironicamente, como se já adivinhasse as elucubrações futuras sobre sua obra, Nelson deu o título de $A$ mulher sem pecado a sua primeira peça, de 1942. Normalmente eclipsada pelo texto e montagem revolucionários de Vestido de noiva, de 1943, a primeira peça já traz todos os elementos do teatro rodriguiano e comprova a indagação apontada por Décio de Almeida Prado: "Ninguém sabia bem como julgá-lo - gênio ou talento superficial e sensacionalista, poeta maldito ou simples manipulador, embora hábil, de enredos melodramáticos?" ${ }^{\prime 5}$ A pergunta, que atravessava a crítica e o público, é pertinente já nesta primeira peça. Como gostava de afirmar Nelson, ela fora escrita para ser uma chanchada e ganhar dinheiro, mas ao fim adquiriu contornos mais dramáticos e foi um fracasso de bilheteria. ${ }^{6}$ De fato, o drama é em determinados momentos tão exagerado que chega a ser cômico, não tanto por apresentar momentos relaxantes, mas sim por levar ao paroxismo as questões levantadas sobre a fidelidade e a loucura. A angústia das personagens é tão exagerada quanto verossímil, paradoxo bem expresso por Santa Rosa, que definia a peça como "cheia de expressão cruel, porém humana: real, mas sob o magnetismo da imaginação; objetiva e concreta, apesar dos fantasmas do delírio demente, pois tudo o que o cérebro concebe é existente". ${ }^{7}$ O cenógrafo, que participou de várias montagens das peças de Nelson, demonstra a percepção de uma crueldade crível, pertencente ao ser humano, ainda que desfigurada pelo delírio; ressalta, ainda, que o que é imaginável pela mente humana existe, pois interfere na vida de quem imagina.

A peça pode ser assim resumida: Olegário é um homem ciumento, obcecado pela dúvida sobre a fidelidade de sua esposa Lídia, bonita e mais jovem; para testá-la, finge-se de paralítico. O ápice dramático ocorre na medida em que o homem que aparenta ser paralítico - pois até o final da peça, nem Lídia nem o público desconfiam da falsa condição - acaba, ironicamente, produzindo a traição que tanto temia quando Lídia foge com Umberto, o chofer.

A peça, dividida em três atos, acontece em tempo contínuo, já que cada ato começa exatamente do ponto em que o outro parou, conferindo uma certa velocidade ao desenrolar das ações das personagens. Já na primeira cena, somos confrontados com a excitação contínua de Olegário, que impulsiona sua cadeira de

\footnotetext{
${ }^{5}$ PRADO. A personagem no teatro, p. 53.

${ }^{6}$ CASTRO. O anjo pornográfico: a vida de Nelson Rodrigues, p. 152.

7 SANTA ROSA. A mulher sem pecado, p. 282.
} 
rodas de um extremo ao outro do palco. Há uma menina que representa Lídia aos dez anos, de vestido curto, bem acima do joelho, que "só existe na imaginação doentia do paralítico". ${ }^{8}$ Além da menina, outros produtos do inconsciente comparecerão à cena: o fantasma da falecida primeira esposa - que descobriremos que traíra Olegário - e a voz interior desse falso paralítico. Esses três elementos, representando o que se passa na mente da personagem, constituem a grande contribuição de Nelson em meio a um cenário teatral sem densidade psicológica como o da década de 1940. Como aponta Décio de Almeida Prado, no teatro, ao contrário do romance, o espectador não tem acesso direto à consciência moral ou psicológica da personagem; como instrumentos principais para superar tal restrição, havia o confidente, o aparte e o monólogo. ${ }^{9} \mathrm{O}$ teatro do século 20 inovou na solução dessa limitação, e vemos em $A$ mulher sem pecado uma das primeiras tentativas de expressar a psicologia das personagens na cena brasileira; os três planos da peça Vestido de noiva para representar a mente de Alaíde (realidade, memória, alucinação) seriam um passo adiante nessa busca. Dessa forma, temos na primeira peça de Nelson novos instrumentos para a perscrutação do interior das personagens, uma renovação que é vital para o andamento da peça, pois nos permite seguir de perto as próprias considerações de Olegário sobre suas obsessões.

Vejamos: o primeiro ato situa o espectador, mostrando as atitudes extremas de Olegário para seguir todos os passos de Lídia. Os empregados são encarregados de vigiá-la: a empregada Inézia cuida dos telefonemas e telegramas e Umberto vigia Lídia em suas andanças. Qualquer voz diferente ao telefone é motivo de desconfiança; um coxo visto na Confeitaria Colombo e posteriormente nos arredores da casa é também alvo de indagações. Percebemos que o casal vive em clima de tensão. Olegário reclama da mania de Lídia de chamá-lo de "meu filho" e os dois discutem sobre a desconfiança dele. Olegário, ao ouvir de Lídia que ela não tem mistérios, argumentará: "estou dentro de você para saber o que você sente, o que você sonha?"10 "e a sua imaginação?"11 Aqui, Olegário revela claramente sua obsessão: seu ciúme não é meramente prático, ou seja, não atua sobre fatos concretos; trata-se de um permanente estado de sobressalto por não ter controle sobre a imaginação: "seus atos podem ser puríssimos. Mas seus pensamentos nem sempre - seu pensamento, seu sonho. Quem é que vai moralizar o pensamento? 0 sonho? Você, talvez!". ${ }^{12}$ Joel, um empregado do escritório de Olegário, também age como detetive e chega à casa do patrão com a informação de que Lídia tem um amante. A fonte é Sampaio, empregado do escritório e ex-vizinho de Lídia no Grajaú; somos informados de que, na época, ela tinha o apelido de V8, um modelo de carro com curvas, frente proeminente e traseira avantajada, que serviria de gíria para mulher namoradeira de dotes físicos exuberantes. A descoberta o perturba ainda mais, e a voz interior, que o espectador escuta pelo microfone, fica a repetir "V8, V8, V8..." ${ }^{13}$ Há uma nova discussão, em que aparecem as famosas frases

\footnotetext{
${ }^{8}$ RODRIGUES. A mulher sem pecado, p. 9.

${ }^{9}$ PRADO. A personagem no teatro, p. 88-89.

10 RODRIGUES. A mulher sem pecado, p. 22.

${ }^{11}$ RODRIGUES. A mulher sem pecado, p. 23.

12 RODRIGUES, A mulher sem pecado, p. 23.

13 RODRIGUES. A mulher sem pecado, p. 31.
} 
feitas, como "a fidelidade devia ser uma virtude facultativa". ${ }^{14}$ Por fim, Olegário pega um telegrama entregue por Inézia no início do ato e afirma, explosivo: "sabe quem sofreu um acidente? Imagine!? (...) Quem ficou com as pernas esmagadas! Foi ele! Ele, o seu amante! Ficou com as duas pernas esmagadas!"15 É o fim do primeiro ato.

O segundo ato continua justamente desse ponto e há um esvaziamento do drama: Olegário admite que a informação fora uma mentira, uma brincadeira. A partir desse momento, a tensão da peça, sempre intercalada com os exageros cômicos, parece finalmente se estabelecer e mostrar sua força. É quando temos o principal embate entre Olegário e Lídia, no qual ela fará todas as suas acusações e falará sobre suas frustrações:

Lídia - (nervosa) Você não soube ser marido! Ainda hoje, eu quase não sei nada de amor, o que é que eu sei de amor? (...) As minhas amigas me contam coisas (...) E eu fico espantada, espantadíssima (...) Nem abro a minha boca, porque não convém...Eu sou uma esposa que não sabe nada, ou quase (...) No colégio interno, aprendi muito mais que no casamento. Parece incrível!

Olegário - Porque eu respeitava você! (...) Você era esposa, e não amante! E eu não podia, compreendeu? Para a esposa, existe um limite! Lídia - Ah, eu não compreendi, nunca, esse escrúpulo, esse limite! Eu pensando que o casamento era outra coisa - tão diferente - e quando acaba você sempre foi tão escrupuloso! Até me proibia de ler livros imorais. Tinha um cuidado comigo, meu Deus do céu! (agressiva) Tinha alguma coisa, eu - uma mulher casada - ler certos livros?

Olegário - (sombrio) Você nunca falou tanto. ${ }^{16}$

Essas palavras, um dos diálogos centrais da peça, mostram que a insatisfação de Lídia, que estava silenciada, vem à tona com tamanha força que provoca o comentário irônico final de Olegário sobre a súbita expressividade da esposa. Ainda não sabemos se Lídia o traiu em algum momento, porém consideramos que o mais provável é ser ela uma vítima da mente doentia, machista e excêntrica do marido. Olegário nos brinda com suas ideias extravagantes sobre a castidade no casamento, lançando a questão: se ela é jovem e bela e ele, um paralítico, qual é a conseqüência lógica?

Aqui fica claro que a única solução para a satisfação de Lídia é a traição: se descobríssemos que ela o traiu, seríamos capazes de simpatizar com esse pequeno crime, considerando-o uma redenção para a personagem feminina vítima do controle monstruoso do marido, o qual possui ideias machistas e egocêntricas. Adiante, Olegário tecerá com Maurício, irmão de criação de Lídia, considerações filosóficas sobre a questão da fidelidade. Para Olegário, toda mulher "esconde uma infidelidade passada, presente ou futura", ${ }^{17}$ de maneira que não existiria a "mulher incapaz de trair, seja em sonho, pensamento, atos ou palavras". ${ }^{18}$ Maurício afirma que essa mulher existe: Lídia. É quando surge um novo fator: Umberto, acusado por D. Márcia de ter entrado no quarto de Inézia, nega as acusações declarando-se

\footnotetext{
${ }^{14}$ RODRIGUES. A mulher sem pecado, p. 36.

15 RODRIGUES. A mulher sem pecado, p. 36-37.

${ }^{16}$ RODRIGUES. A mulher sem pecado, p. 42-43.

17 RODRIGUES. A mulher sem pecado, p. 51.

18 RODRIGUES. A mulher sem pecado, p. 52.
} 
castrado. É a felicidade para Olegário, que considera o homem castrado o vigia perfeito para Lídia, pois, afinal "é um privilégio ter, em casa, um homem que poderia assistir, tranqüilamente, ao banho de nossa mulher...". ${ }^{19}$ Cada vez mais obcecado, proíbe Lídia de sair do quarto de roupão e considera indecente uma mulher olhar o próprio corpo. É nesse ponto da peça que Olegário, às voltas com o que ele chama de seu inferno interior, parece ter chegado ao ponto máximo da obsessão e da demência. É quando Umberto aparece repentinamente, beija Lídia e as cortinas descem.

O terceiro ato, que continua exatamente da cena do beijo, nos traz mais revelações: Umberto é o conhecido "canalha" rodriguiano, pronto a conseguir vantagens das situações adversas. Lídia, apesar de nunca ter demonstrado interesse pelo chofer, passa gradativamente do medo à atração, e da rejeição inicial chega ao fascínio quando é chamada de "cínica" por Umberto, que afirma gostar de insultar as mulheres de quem gosta. A sexualidade reprimida de Lídia aflora, o que a torna presa fácil de Umberto. Como ela mesma diz a Olegário, o que ele parece desejar é que ela não seja fiel, ou "pelo menos está fazendo tudo para que eu seja infiel. Não está? Quem meteu na minha cabeça a idéia do pecado? É a sua idéia fixa!" ${ }^{20}$ Lídia chega ao desespero e, sozinha, revela sua fantasia de ser seviciada em um lugar deserto, aterrorizando-se com seus próprios desejos. Logo depois, triunfantemente, Olegário revela a Maurício que não era paralítico, mas desejara fazer uma experiência para testar a fidelidade da mulher, teste no qual essa passara com louvor. É quando Inézia entra com uma carta, que nos é lida pelo microfone: "Olegário! Parto com Umberto. Nunca mais voltarei. Não quero seu perdão. Adeus. Lídia. Nunca mais voltarei. Nunca mais...".21 Ao som da carta, Olegário encosta um revólver na fronte e o pano cai.

Percebemos que a peça é um dramalhão caricato, mas os toques cômicos não desanuviam a tensão contínua. Olegário tortura Lídia e a si mesmo com sua farsa de maneira tão planejada e detalhista que parece ter um prazer no jogo em si, como que esvaziado de qualquer sentimento mais nobre. Não conseguimos lamentar o final infeliz de Olegário porque o vemos como o responsável por sua própria queda. Seu ciúme é inicialmente sem razão, e de tão violento acaba por produzir a razão: a primeira impressão é que ele conduz a esposa ao adultério, em uma ironia trágica.

Uma pergunta nos vem à mente: quem é a mulher sem pecado do título? Se a resposta for Lídia, devemos compreender em que medida ela seria sem pecado, visto que acaba por cometer um ato pecaminoso ao trair o marido. Além de Lídia, temos mais três mulheres na peça: Inézia, criada subserviente e infeliz, D. Márcia, sogra de Olegário e ex-lavadeira, que vive com os dois de favor, e D. Aninha, mãe de Olegário, descrita por Nelson na didascália como "doida pacífica", pois passa a peça inteira muda a enrolar um paninho, como que personificando a loucura temida tanto por Olegário quanto por Lídia. Como as três são secundárias, os holofotes se voltam para Lídia.

Lídia parece ser inocente a princípio. No entanto, na condição de mulher oprimida, já traz em si todas as predisposições para a traição. Não parece haver

${ }^{19}$ RODRIGUES. A mulher sem pecado, p. 59.

${ }^{20}$ RODRIGUES. A mulher sem pecado, p. 79-80.

${ }^{21}$ RODRIGUES. A mulher sem pecado, p. 88. 
outro caminho para escapar da pressão intolerável de um casamento insatisfatório tanto afetiva quanto sexualmente. Seu pecado parece ser a única possibilidade de redenção, mais ainda assim não é um caminho libertador: sua rendição à sedução de Umberto não é a rendição ao amor, à paixão, à esperança de felicidade. Ele se rende como revolta contra a opressão de Olegário. Umberto é sua única possibilidade. Sua fuga com o chofer não é um final feliz, mas a única solução acessível. Sendo assim, o crime que ela comete, além de ser pálido frente à perseguição monstruosa de Olegário, parece não lhe dar a satisfação final, a redenção. Sua traição, como ato condenável, não Ihe traz a libertação. Como seu crime foi forçado, o prazer que ela tira desse é pequeno. Isso, no entanto, não a isenta. Se ela é a mulher sem pecado, o é por simplesmente não ter sido o motor central do seu pecado. É como se Lídia fosse um pecadora passiva, pré-fabricada. Sem a pressão de Olegário, é possível que não pecasse e continuasse reprimindo sua insatisfação. Dessa forma, ela é uma espécie de criminosa ainda sem ficha, uma pecadora involuntária e sem experiência. Olegário e Umberto ativam um componente em Lídia que poderia continuar adormecido por muito tempo.

Dessa forma, a mulher sem pecado que é Lídia apenas começou a ativar sua porção obscura; é a pecadora infante do teatro rodriguiano. Em outras peças de Nelson, o pecado fará sua aparição de maneira mais desinibida, mais redentora, proporcionando mais satisfação às personagens antes do castigo final. Olegário e Umberto são as figuras monstruosas, pecadores experimentados, capazes de atos abomináveis - seus comportamentos desviantes parecem estar em um combate que só resultará em um vencedor. O contraste entre os dois e Lídia é marcante, pois ainda é possível ver de maneira razoavelmente clara a canalhice versus a inocência, embora a primeira já exista embrionária em Lídia.

Adriana Facina é perspicaz na análise das personagens rodriguianas: "para Nelson Rodrigues, todos os homens têm em si duas metades, uma "face linda" e outra "face hedionda", centauros parcialmente Deus e parcialmente Satã. As imagens que apareciam freqüentemente nos textos de Nelson representando essas duas metades dos seres humanos eram os santos e os canalhas". ${ }^{22}$ Para 0 dramaturgo, os extremos se tocam de maneira paradoxal. A porção canalha pode ser interpretada como uma espécie de mal essencial e constitutivo do ser humano, mas é também uma reação a uma sociedade repressiva e hipócrita. Desse ponto de vista, a Zulmira de $A$ falecida (1953) é uma Lídia já avançada, que mantém as duas facetas em atrito desesperador. A sua obsessão por um enterro luxuoso e triunfante é sua maneira de conseguir a satisfação que não tivera em vida. Ao trair o marido Tuninho, ela exibe a face canalha como uma reação à infelicidade. Sua doença mal diagnosticada e seu posterior medo de ter a traição descoberta geram a culpa e o desejo de redenção pela morte. Porém, o seu pecado não é tão involuntário como de Lídia: a própria Zulmira é agente de seu crime e obtém dele uma momentânea redenção. Contudo, ela não poderia ficar ilesa no universo rodriguiano: seu pecado é voluntário e necessário, ela obtém dele alguma satisfação, mas deve dar a vida para purificar tal desvio.

Nelson concebia a vida como espaço de falsidades e hipocrisias que só permitia que a felicidade acontecesse por uma brecha desviante e momentânea,

22 FACINA. Santos e canalhas: uma análise antropológica da obra de Nelson Rodrigues, p. 15. 
visto que o castigo viria a galope. Assim, seu comentário relativo ao potencial pedagógico de suas peças deve ser lido com certo cuidado. Pode-se afirmar que o autor era um crente fervoroso na capacidade catártica do teatro. Quando disse que "ninguém faz o teatro brasileiro. Marx e Brecht cretinizaram toda uma geração de autores e diretores patrícios", 23 o dramaturgo se referia às concepções de teatro épico de Brecht, que pregavam o distanciamento para a conscientização social e aboliam a catarse, vista como causadora da paralisia e da rendição. A lógica era: se o espectador vai se emocionar, chorar, se desesperar, como vai reagir? Nelson seguiu escrevendo durante os anos da ditadura militar, contexto de uma arte militante de esquerda que o via como um alienado. Contudo, para Nelson, era justamente a catarse teatral que fazia com que os espectadores não cometessem os crimes na vida real, dando-lhes o prazer da subversão sem a responsabilidade do ato. Nelson afirmava que

a ficção, para ser purificadora, precisa ser atroz. O personagem é vil para que não o sejamos. Ele realiza a miséria inconfessa de cada um de nós. A partir do momento em que Ana Karenina, ou a Bovary, trai, muitas senhoras da vida real deixarão de fazê-lo. ${ }^{24}$

Dessa forma, a ironia rodriguiana possui um subtexto grave: sendo o mundo um palco em que as personagens são frustradas e reprimidas, o teatro é a possibilidade de realização, de alívio momentâneo sem que haja desordem social. Embora a esquerda que ele chamava de "festiva" acenasse, após a etapa da desordem social, com a possibilidade de um mundo de igualdade sem repressão, o autor observava os governos socialistas e temia esse mundo prometido. Para ele, o teatro ainda era a possibilidade de subversão, mas não por representar um novo mundo engajado, mas por retratar criticamente o mundo como ele era, como finais infelizes, castigos e o lema "o crime não compensa". Nelson era um descrente da sociedade livre e sem culpa, não tanto por ser moralista no sentido pejorativo, mas por não acreditar que o ser humano fosse capaz de forjar tal mundo de felicidade. Criar um teatro que tratasse de temas perturbadores era, para o autor, o único engajamento possível. Ao chamar o seu teatro de desagradável, Nelson parece ter selado a recepção de suas peças:

Com Vestido de noiva, conheci o sucesso; com as peças seguintes, perdi-o, e para sempre. Não há nesta observação nenhum amargor, nenhuma dramaticidade. Há, simplesmente, o reconhecimento de um fato e sua aceitação. Pois a partir de Álbum de família - drama que se seguiu a Vestido de noiva - enveredei por um caminho que pode me levar a qualquer destino, menos ao êxito. Que caminho será este? Respondo: de um teatro que se poderia chamar assim - desagradável. Numa palavra, estou fazendo um teatro desagradável, peças desagradáveis. No gênero destas, incluí, desde logo, Álbum de família, Anjo negro e a recente Senhora dos afogados. E por que peças desagradáveis? Segundo já se disse, porque são obras pestilentas, fétidas, capazes, por si sós, de produzir o tifo e a malária na platéia. ${ }^{25}$

A aceitação de um teatro desagradável seria para Nelson o cúmulo de um mundo feliz: um mundo que aceitasse debater e se emocionar com tabus seria o mais

${ }^{23}$ RODRIGUES. Flor de obsessão: as 1000 melhores frases de Nelson Rodrigues, p. 163.

24 RODRIGUES. Flor de obsessão: as 1.000 melhores frases de Nelson Rodrigues, p. 161.

${ }^{25}$ RODRIGUES. Teatro completo, p. 275. 
próximo possível da perfeição. O ideal não seria um mundo em que o crime compensasse ou um mundo em que a ideia de pecado tivesse sido abolida - esses eram mundos inconcebíveis. O mundo ideal rodriguiano é o mundo imperfeito que se olha no espelho e não tem vergonha de falar de si. Considerando que sua obra entre peças, crônicas e romances - voltou a ser publicada, lida e encenada com fervor nos anos de 1990 e experimenta nos anos de 2000 um novo boom, talvez estejamos um pouco mais próximos desse mundo ideal imperfeito.

Abstract:

This article searches for crimes, sins and monstrosities in the dramatic works of Nelson Rodrigues. The aim is to discover the meaning of those terms and their pertinence for understanding Rodrigues' works. The main focused play is the first and almost forgotten one, A mulher sem pecado, from 1942, which brings the obsessive themes of the whole drama of the playwright.

Keywords: Theater; catharsis; obsession; crime

Referências

BRECHT, Bertolt. Estudos sobre teatro. Rio de Janeiro: Nova Fronteira, 1978.

CASTRO, Ruy. O anjo pornográfico: a vida de Nelson Rodrigues. São Paulo: Companhia das Letras, 1992.

FACINA, Adriana. Santos e canalhas: uma análise antropológica da obra de Nelson Rodrigues. Rio de Janeiro: Civilização Brasileira, 2004. 3

FREUD, Sigmund. O mal-estar na civilização. Rio de Janeiro: Imago, 1969.

MAGALDI, Sábato. Nelson Rodrigues: dramaturgias e encenações. São Paulo: Perspectiva, 1992.

MAGALDI, Sábato. Teatro da obsessão: Nelson Rodrigues. São Paulo: Global, 2004.

PRADO, Décio de Almeida. A personagem no teatro. In: CANDIDO, Antonio (Org.). A personagem de ficção. São Paulo: Perspectiva, 2004. p. 83101.

PRADO, Décio de Almeida. O teatro brasileiro moderno. 2. ed. São Paulo: Perspectiva, 2003. 
RAMOS, Nuno. A noiva desnudada. Revista Piauí, São Paulo, n. 7, p. 56-59, abr. 2007.

RODRIGUES, Nelson. Flor de obsessão: as 1.000 melhores frases de Nelson Rodrigues. São Paulo: Companhia das Letras, 1997.

RODRIGUES, Nelson. A mulher sem pecado. Rio de Janeiro: Nova Fronteira, 2005..

RODRIGUES, Nelson. Teatro completo. 2. ed. Rio de Janeiro: Nova Fronteira, 2004. 4 V.

RODRIGUES, Nelson. Teatro desagradável. In: __. Teatro completo. 2. ed. Rio de Janeiro: Nova Fronteira, 2004. p. 273-278. v. 1.

SANTA ROSA, Tomás. A mulher sem pecado. In: RODRIGUES, Nelson. Teatro completo. 2. ed. Rio de Janeiro: Nova Fronteira, 2004. p. 282. v. 1.

WALDMAN, Berta; VOGT, Carlos. Nelson Rodrigues: flor de obsessão. São Paulo: Brasiliense, 1985. 